American Journal of Applied Sciences 7 (2): 248-251, 2010

ISSN 1546-9239

(C) 2010 Science Publications

\title{
A Novel Carbon Steel Pipe Protection Based on Radial Basis Function Neural Network
}

\author{
Sami Abulnoun Ajeel \\ Department of Production and Metallurgy Engineering, \\ University of Technology, Baghdad, Iraq
}

\begin{abstract}
Problem statement: The cost due to corrosion Damage have estimated to be 3-4\% of their gross national product which significantly Countries problem around the world. Approach: In this study, a novel carbon steel pipe protection based on RBFNN was proposed. The RBFNN used to predict the minimum current density required in impressed current cathodic protection to protect low carbon steel pipe. Learning data was performed by using a 30 samples test with different concentration $\mathrm{C} \%$, temperature $\mathrm{T}$, distance $\mathrm{D}$ and $\mathrm{pH}$. The RBFNN model has four input nodes representing the (concentration $\mathrm{C} \%$, temperature $\mathrm{T}$, distance $\mathrm{D}$ and $\mathrm{pH}$ ), eight nodes at hidden layer and one output node representing the min. current density. Results: Generalization test used 5 data samples taken from the experimental results other than those data samples used in the learning process to check the performance of the neural network on these data. Conclusion: In addition, the experimental results indicate that proposed system can be used successfully to obtain minimum cathodic protection current density to protect low carbon steel pipes.
\end{abstract}

Key words: Corrosion, carbon steel pipe, RBFNN

\section{INTRODUCTION}

Corrosion is an electrochemical reaction based on universal laws of nature. All metallic structures corrode, steel, for example is a man made substance produced from iron oxide. The energy added in the refining process is unstable given a suitable environment; steel will release this energy and return to its natural state of iron ore (Uhlig and Winston, 1985).

Many researcher focus on Galvanic cathodic protection uses anodes which have a natural potential more reactive than that of the structure being protected (Stephen, 1999; White and Sofge, 1992). For steel structures, magnesium and zinc have proven practical for buried applications, while aluminum and zinc are used to protect marine structures. It is also possible to use an external power source to impress current on a relatively inert material such as cast iron, graphite or mixed metal oxide anodes; this method is called impressed current cathodic protection (Uhlig and Winston, 1985). Sami and Ghalib (2008a) studied cathodic protection system for low carbon steel pipe. This system was used to investigate the influence of various conditions on the minimum cathodic protection current that would provide a full cathodic protection for steel tube immersed in sea water. The variable conditions studied are concentration of (0.01-3.5\%) $\mathrm{NaCl}$, temperature $\left(30-50^{\circ} \mathrm{C}\right)$, distance between pipe (cathode) and graphite electrode (anode) of (10-20) cm and $\mathrm{PH}$ solution of (5.0-9.0) using a selected range of these conditions, the experimental results indicated that the cathodic protection current density increases with increasing temperature, concentration and $\mathrm{PH}$ respectively. The current density also slightly increases with an increase in distance between cathode and anode. Intelligent control is now becoming a common tool in many engineering and industrial applications. It has the ability to comprehend and learn about plants, disturbances, environment and operating conditions (Miller et al., 1990; Rumethart et al., 1986). Some examples of the factors to be learned are plant characteristics such as its static and dynamic behaviors (White and Sofge, 1992; Dayhoff, 1990).

In this study, the cathodic protection method for corrosion prevention requires identification of the minimum current density that gives the full corrosion protection with the presence of certain environment variables was proposed. The RBFNN used to identify this minimum current density taking the environment variables as input and using the practical results data for the learning process. This can be done by creating a mathematical model for the process and choosing the best neural network architecture, decision function and learning algorithm for this application. 
Am. J. Applied Sci., 7 (2): 248-251, 2010

\section{MATERIALS AND METHODS}

Material: The material used in this work is low carbon steel pipe (ASTM A179-84a) type as X60 of $3 \mathrm{~cm}$ out side diameter and $2 \mathrm{~cm}$ in side diameter. Analysis of these specimens was carried out using (spectrometer DV.4) in Nasser Company. Table 1 shows the nominal and the analytical chemical compositions of the carbon steel pipe.

Solution: The solution was prepared experimentally in different concentrations of $(0.01,0.1,1,2$ and $3.5 \%)$ by adding different weights of $(0.1,1,10,20$ and 35) gm sodium chloride $\mathrm{NaCl}$ to $1 \mathrm{~L}$ of distilled water. The $\mathrm{NaCl}$ purity $=99.55 \%$, supplied by BDH Ltd. was used in the experiment.

The proposed method: Experimental procedure: The tube specimen was cut with dimensions $10 \mathrm{~cm}$ length and $3 \mathrm{~cm}$ outside diameter and these specimens were used for all impressed current cathodic protection procedures.

The electrolyte was stirred by using mechanical stirrer to obtain a homogenous solution and then using the heater controller in the bath to set the solution at the required temperature and after achieving the temperature homogenization, the experiments were started.

Before starting each run, the cross sectional area of one end of the specimens closed using a rubber stopper then covered by thermal silicon to ensure that no water enter the inner tube surface and the other end isolated using plastic tube. The electrical connection (connection point) then fixed into plastic stand and passed through the above plastic tube. An auxiliary electrode entered the electrolyte at $5 \mathrm{~cm}$ from solution surface level then the electrical circuit (ICCPS) was connected as shown in Fig. 1.

After switching on the electrical circuit and supplying the Ecorr of (-850 $\mathrm{mV}$ Vs SCE) from potentiostat the impressed current was recorded at intervals of $1 \mathrm{~min}$ over a period of $20 \mathrm{~min}$ by using the digital ammeter. The experiments were ended when the (icp) reached the steady state value giving the best value of impressed current cathodic protection.

In order to obtain the effects of the studied parameters on (ICCPS) like temperature, distance between cathode and anode, electrolyte concentration and $\mathrm{PH}$, the above procedures were repeated for each run, but this was done after the glass bath was emptied from the used solution and washed by distilled water to ensure that no salt was left in the glass bath.
Table 1: Experimental $\mathrm{i}_{\mathrm{cp}}$ at $\mathrm{E}_{\mathrm{cp}}(-850 \mathrm{mV})$

\begin{tabular}{lllll}
\hline $\mathrm{NaCl} \mathrm{C}(\%)$ & $\mathrm{T}\left({ }^{\circ} \mathrm{C}\right)$ & $\mathrm{D}(\mathrm{cm})$ & $\mathrm{pH}$ & $\mathrm{i}_{\mathrm{cp}}\left(\mu \mathrm{A} \mathrm{cm}^{-2}\right)$ \\
\hline 3.50 & 30 & 10 & 9.0 & 26.648 \\
2.00 & 30 & 20 & 8.5 & 24.840 \\
1.00 & 30 & 15 & 7.0 & 24.091 \\
0.10 & 30 & 10 & 6.5 & 24.222 \\
0.01 & 30 & 10 & 5.0 & 23.553 \\
0.01 & 30 & 20 & 5.0 & 23.919 \\
3.50 & 35 & 15 & 9.0 & 33.129 \\
2.00 & 35 & 20 & 8.5 & 32.726 \\
1.00 & 35 & 10 & 7.0 & 30.761 \\
0.10 & 35 & 20 & 6.5 & 29.918 \\
0.01 & 35 & 15 & 5.0 & 29.228 \\
0.10 & 35 & 10 & 7.0 & 29.001 \\
3.50 & 40 & 20 & 9.0 & 40.787 \\
2.00 & 40 & 15 & 8.5 & 39.267 \\
1.00 & 40 & 10 & 7.0 & 38.825 \\
0.10 & 40 & 15 & 6.5 & 37.511 \\
0.01 & 40 & 10 & 5.0 & 36.922 \\
1.00 & 40 & 20 & 7.0 & 39.115 \\
3.50 & 45 & 10 & 9.0 & 45.949 \\
2.00 & 45 & 20 & 8.5 & 44.713 \\
1.00 & 45 & 15 & 7.0 & 43.883 \\
0.10 & 45 & 20 & 6.5 & 43.125 \\
0.01 & 45 & 15 & 5.0 & 42.000 \\
2.00 & 45 & 10 & 8.5 & 44.018 \\
3.50 & 50 & 10 & 9.0 & 52.641 \\
2.00 & 50 & 15 & 8.5 & 51.405 \\
1.00 & 50 & 10 & 7.0 & 50.912 \\
0.10 & 50 & 15 & 6.5 & 49.416 \\
0.01 & 50 & 20 & 5.0 & 48.026 \\
3.50 & 50 & 20 & 9.0 & 53.157 \\
\hline & & & &
\end{tabular}

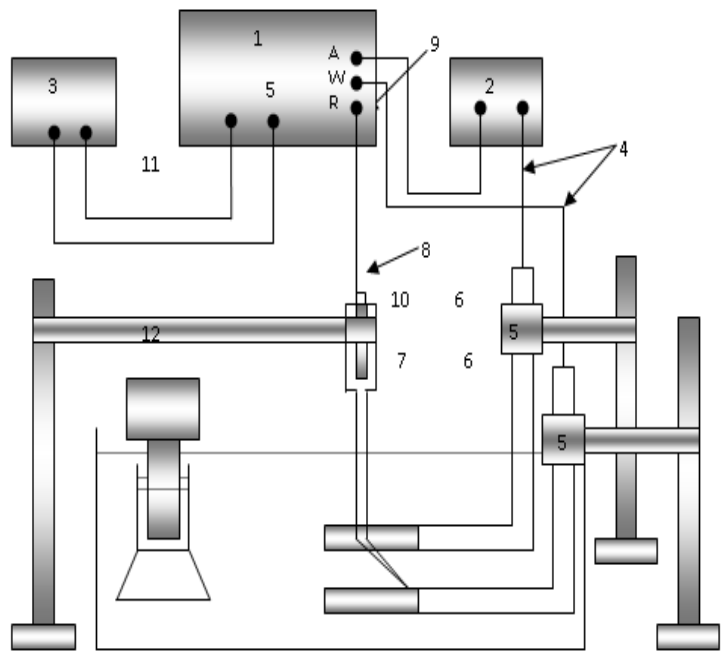

Fig. 1: Experimental setup of cathodic protection (ICCPS), (1) potentiostat; (2) voltmeter; (3) ammeter, (4) connecting wires; (5) stands; (6) pipe plastic; (7) cathode; (8) lugging capillary; (9) Saturated Calomel Electrode (SCE); (10) anode; (11) heater; (12) water bath of distilled water 
RBFNN model for cathodic protection: From the examples ANN captures the domain knowledge (De La Mata-Moya et al., 2007). ANN can handle continuous as well as discrete data and have good generalization capability as with fuzzy expert systems. An ANN is a computational model of the brain. They assume that computation is distributed over several simple units called neurons, which are interconnected and operate in parallel thus known as parallel distributed processing systems or connection systems. Implicit knowledge is built into a neural network by training it. Several types of ANN structures and training algorithms have been proposed.

The basic form of RBF architecture involves entirely three different layers. The input layers is made $\mathrm{n}$, of source nodes while the second layer is hidden layer of high enough dimension which senses a different purpose from that in a multilayer perception.

The output layer supplies the response of the network to the activation patterns applied to the input layer. The tram formation from the input layer to hidden is nonlinear whereas the transformation from the hidden from unit to the output layer is linear.

The transfer function for a radial basis neuron is:

$$
\operatorname{radbas}(\mathrm{n})=\mathrm{e}-\mathrm{n}_{2}
$$

This function calculates a layer's output from its net input.

For effective current predicting of cathodic protection, the selection of proper inputs and outputs of ANN, structure of the network and training of it using appropriate data should be done with utmost care. In the present study, inputs are selected as four inputs these are (concentration $\mathrm{C} \%$, temperature $\mathrm{T}$, distance between cathode and anode $\mathrm{D}$ and $\mathrm{pH}$ solution) and it have one output which is the predicted cathodic protection current density as shown in Fig. 2.

\section{RESULTS}

The experiment results were used to train the neural network which have been constructed and trained using 25 data samples from the experimental data and 5 samples were used for generalization test of the trained neural network (Sami and Ghalib, 2008b) as shown in Table 1.

The third step was the generalization test for the neural network. The generalization test means to test the neural network on data samples other than those data samples used in the learning process and to check the performance of the neural network on these data. In our case, we used 5 data samples taken from the experimental results for the generalization test. This neural network was simulated using the scientific and engineering package MATALB ${ }^{\circledR}$ 7.2.

\section{DISCUSSION}

From the analysis of the results in Table 1, it is observed that the accuracy of the RBFNN method was slightly superior when compared to the experimental on account of Mean Average Error (MAE). Figure 3 shows a plot of experimental against corresponding RBFNN prediction. A linear correlation can be observed and the correlation coefficient was found Table 2 .

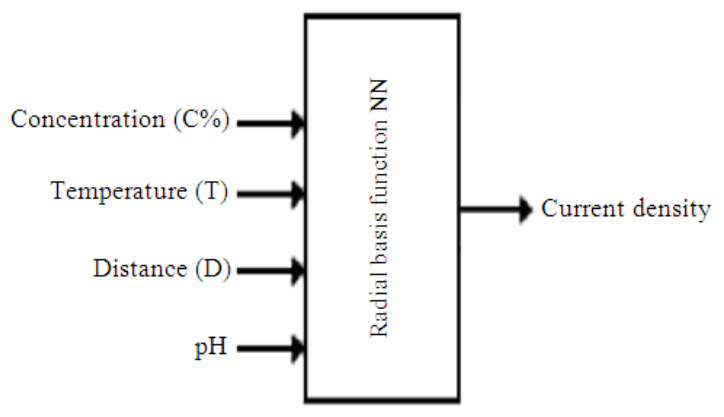

Fig. 2: RBFNN model control



Fig. 3: Comparison of RBFNN with the experimental output

Table 2: Comparison between experimental and RBFNN

\begin{tabular}{llllll}
\hline $\mathrm{C}(\%)$ & $\mathrm{T}\left({ }^{\circ} \mathrm{C}\right)$ & $\mathrm{D}(\mathrm{cm})$ & $\mathrm{pH}$ & $\begin{array}{l}\mathrm{i}_{\mathrm{cp}}\left(\mu \mathrm{A} \mathrm{cm} \mathrm{cm}^{-2}\right) \\
\text { experimental }\end{array}$ & $\begin{array}{l}\mathrm{i}_{\mathrm{cp}}\left(\mu \mathrm{A} \mathrm{cm} \mathrm{cm}^{-2}\right) \\
\mathrm{RBFNN}\end{array}$ \\
\hline 3.5 & 30 & 10 & 9.0 & 26.648 & 26.534987 \\
1.0 & 30 & 15 & 7.0 & 24.091 & 24.109870 \\
1.0 & 35 & 10 & 7.0 & 30.761 & 30.239840 \\
0.1 & 45 & 20 & 6.5 & 43.125 & 43.297650 \\
3.5 & 50 & 20 & 9.0 & 53.157 & 53.278930 \\
\hline
\end{tabular}




\section{CONCLUSION}

In the present study the Radial Basis Function Neural Network (RBFNN) has been explored used for cathodic system protection to obtain the current density for different application conditions and this was obvious from the generalization test. The simulation data from experimental test has been used for training and testing. The Simulation results show that RBF can be very successively identifying minimum current density taking the environment variables. This means that it can solve many problems that have been costly and experimental difficulties.

\section{REFERENCES}

Dayhoff, J.E., 1990. Neural Network Architectures: An Interdiction. Van Nostrand Reinhold, New York. ISBN: 0442207441, pp: 259.

De La Mata-Moya, D., P. Jarabo-Amores, M. RosaZurera, R. Vicen-Bueno and J.C. Nieto-Borge, 2007. Neural network based approaches for detecting signals with unknown parameters. Proceeding of the IEEE International Symposium on Intelligent signal Processing, Oct. 3-5, IEEE Xplore Press, Alcala de Henares, pp: 1-6. DOI: 10.1109/WISP.2007.4447634
Miller, W.T., R.S, Sutton and P.J. Werbos, 1990. Neural Networks for Control. 1st Edn., MIT Press, Cambridge, MA., ISBN: 9780262132619, pp: 524.

Rumethart, D.E., J.L. McClelland, 1986. Parallel Distributed: Processing Exploration in the Micro Structure of Cognition. Vol. 1, MIT Press, Cambridge, MA., ISBN:0-262-68053-X, pp: 547.

Sami, A.A. and A.A. Ghalib, 2008a. Variable conditions effect on polarization parameters of impressed current cathodic protection of low carbon steel pipes. Eng. Technol., 26: 1-12. $\mathrm{http} / / /$ uotechnology.edu.iq/tec_magaz/volume2620 08/No6/Researches/5.pdf

Sami, A.A. and A.A. Ghalib, 2008b. Application of artificial neural network for cathodic protection of low carbon steel pipes. Eng. Technol. J., 26.

Stephen, K.L., 1999. Electrochemistry. Simon Fraser University.

Uhlig, H.H. and R.W. Revie, 1985. Corrosion and Corrosion Control. 3rd Edn., Wiley-Interscience, ISBN: 10: 0471078182, pp: 464.

White, D.A. and D.A. Sofge, 1992. Handbook of Intelligent Control: Neural, Fuzzy, and Adaptive Approaches . Van Nostrand Reinhold, New York. ISBN: 0442308574, pp: 250. 